\title{
Power quality optimization through D-STATCOM in Aizawl, Mizoram, India
}

\author{
Lalhungliana, Nimesh Kumar Singh, Sanjeev Pareek \\ Department of Electrical and Electronics Engineering, National Institute of Technology Mizoram, Aizawl 796012, Mizoram, India
}

Corresponding author: sanjeev.eee.phd@nitmz.ac.in

\begin{abstract}
The power quality concerns are augmenting day by day due to the growth of loading requirements. In this paper, we address these concerns while trying to provide the solutions. With the advancement of technology, the power quality concerns can be handled efficiently by flexible alternating current transmission system (FACTS) devices such as distribution static shunt synchronous compensator (DSTATCOM ), static volt-ampere reactive compensator (SVC), static synchronous series compensator (SSSC), thyristor-controlled series compensator (TCSC), unified power flow controller (UPFC), etc. This paper presents the solutions for power quality issues related to M izoram with the help of D-STATCOM. D-STATCOM enhances the power quality by varying the various parameters of the system and make the system more flexible. We propose a MATLAB Simulink model of D-STATCOM which demonstrates the control of active and reactive power and hence maintains the voltage profile. In Mizoram, during peak hours Undervoltage is a frequent phenomenon which causes damage to various domestic appliances as well as it significantly affects the electrical equipment of small industries. By incorporating D-STATCOM in the existing system at the distribution level we can greatly improve the voltage profile of distribution system, which not only provide better power quality but also increase the lifespan of domestic as well as small industrial equipment, by this proposed modification in existing system the revenue of distribution, as well as customer satisfaction, can be improved.
\end{abstract}

Keywords: D-STATCOM, power scenario in Mizoram, voltage stability.

\section{INTRODUCTION}

As we know the population of the world increasing at a devastating rate so the demand for electricity is augmenting rapidly (Census, 2011). This problem is affecting nations with huge population and scare resources like India, which is growing in industrialization rapidly in recent years (Indian Electrical Equipment Industry Mission Plan, 2012-2022). Due to diversified loads, our conventional power system is unable to maintain constant voltage profile at the consumer end (Hingorani and Gyugyi, 2001; Wang et al., 2011; Lee et al., 2013; Saravanan et al., 2014). As a result of these constant voltage fluctuations which occur during peak load periods are the outcomes of uneven distribution of single-phase loads, an impedance of transmission lines and the loading types (Sensarma et al., 2001).

Due to less population and geographically landlocked state, Mizoram is unable to keep pace with the develop- mental activities happening in rest of the country, it also hampered the development in power sector of Mizoram (NEDP, 2018). As per the data acquired by the officers of state load dispatch centre (SLDC) and different substations we came to know that voltage profile of Mizoram is totally dependent on the incoming grid voltage and there are barely any power conditioning devices like DSTATCOM, capacitor banks, SVC, TCSC, etc. with the advent of latest technological solutions like D-STATCOM, and other power quality improvement devices which are capable of stabilizing voltage to a desired level and will provide quality power to citizens of Mizoram (Reed et al., 2000; Lee et al., 2010).

\section{Materials AND MethodS}

According to IEEE, D-STATCOM is the static synchronous compensator connected in shunt with the line to alleviate the impact of dips and peaks of voltage sensitive 
loads, voltage flicker and current harmonics. It is also used to control the reactive power and voltage regulation for the betterment of power quality at the consumer end in low-voltage distribution networks.

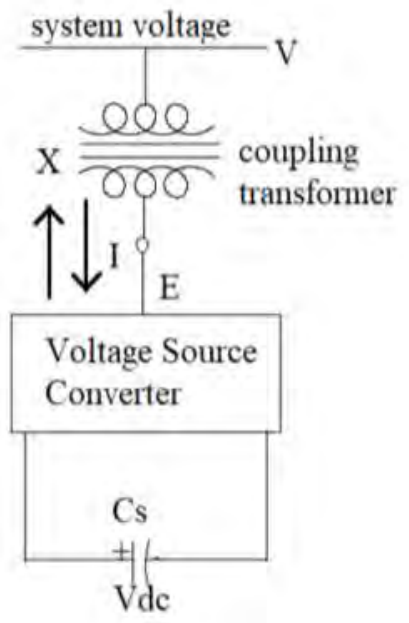

Figure 1: Simplified structure of D-STATCOM.

The basic circuit diagram of D-STATCOM is shown in Figure 1. D-STATCOM consists of a coupling transformer (with leakage inductance) in series with DC to AC switching converter which is parallelly connected to a capacitor of high capacitance. D-STATCOM is connected in shunt with the line.

$$
I=\frac{V-E}{X}
$$

Where $I$ is the exchange current between D-STATCOM and the System, $V$ is the system voltage and $E$ is the $D$ STATCOM voltage. $X$ is the transformer leakage inductance.

$$
Q=\frac{1-\frac{E}{V}}{X} V^{2}
$$

Where $Q$ is the reactive power.

When the voltage across the line is greater than the voltage across D-STATCOM, it acts as a reactor which provides negative VAR compensation (inductive compensation) to the line and stabilizes the voltage profile of line by controlling peaks in the line voltage at the distribution level. Similarly, when the voltage across the line is lesser than the voltage across D-STATCOM, it acts as a capacitor which provides positive VAR compensation (capacitive compensation) to the line and stabilizes the voltage profile of line by controlling the dips in line voltage at the distribution level. This maintains the consumer end voltage at a desired voltage level and refines the power quality as per required standards. D-STATCOM is also capable of handling active power in the system, i.e. It can supply active power to the system with the help of capacitor
Table 1: Demand and generation during peak loads for August 2018.

\begin{tabular}{|c|c|c|c|c|}
\hline $\begin{array}{r}\text { SI } \\
\text { no. }\end{array}$ & Date & $\begin{array}{c}\text { Peak Load } \\
\text { (MW) }\end{array}$ & $\begin{array}{c}\text { Total local } \\
\text { generation } \\
\text { (MW } \mathbf{~}\end{array}$ & $\begin{array}{c}\text { Demand } \\
\text { fulfilled } \\
\text { from grid }\end{array}$ \\
\hline 1 & $01 / 08 / 2018$ & 89.46 & 25.05 & 64.41 \\
\hline 2 & $02 / 08 / 2018$ & 85.78 & 27.71 & 58.07 \\
\hline 3 & $03 / 08 / 2018$ & 89.77 & 27.76 & 62.01 \\
\hline 4 & $04 / 08 / 2018$ & 88.75 & 27.79 & 60.96 \\
\hline 5 & $05 / 08 / 2018$ & 93.4 & 27.83 & 65.57 \\
\hline 6 & $06 / 08 / 2018$ & 81.66 & 27.38 & 54.28 \\
\hline 7 & $07 / 08 / 2018$ & 91.13 & 27.72 & 63.41 \\
\hline 8 & $08 / 08 / 2018$ & 89.54 & 25.68 & 63.86 \\
\hline 9 & $09 / 08 / 2018$ & 88.84 & 26.94 & 61.9 \\
\hline 10 & $10 / 08 / 2018$ & 86.19 & 27.8 & 58.39 \\
\hline 11 & $11 / 08 / 2018$ & 97.24 & 27.75 & 69.49 \\
\hline 12 & $12 / 08 / 2018$ & 89.32 & 27.22 & 62.1 \\
\hline 13 & $13 / 08 / 2018$ & 90.31 & 25.8 & 64.51 \\
\hline 14 & $14 / 08 / 2018$ & 73.67 & 22.73 & 50.94 \\
\hline 15 & $15 / 08 / 2018$ & 77.7 & 27.86 & 49.84 \\
\hline 16 & $16 / 08 / 2018$ & 84.18 & 28.73 & 55.45 \\
\hline 17 & $17 / 08 / 2018$ & 84.37 & 28.01 & 56.36 \\
\hline 18 & $18 / 08 / 2018$ & 87.15 & 26.85 & 60.3 \\
\hline 19 & $19 / 08 / 2018$ & 80.78 & 28.64 & 52.14 \\
\hline 20 & $20 / 08 / 2018$ & 85.14 & 27.32 & 57.82 \\
\hline 21 & $21 / 08 / 2018$ & 82.72 & 27.14 & 55.58 \\
\hline 22 & $22 / 08 / 2018$ & 86.72 & 27.44 & 59.28 \\
\hline 23 & $23 / 08 / 2018$ & 87.12 & 27.36 & 59.76 \\
\hline 24 & $24 / 08 / 2018$ & 87.31 & 27.19 & 60.12 \\
\hline 25 & $25 / 08 / 2018$ & 89.66 & 24.46 & 65.2 \\
\hline 26 & $26 / 08 / 2018$ & 80.51 & 26.63 & 53.88 \\
\hline 27 & $27 / 08 / 2018$ & 86.76 & 27.02 & 59.74 \\
\hline 28 & $28 / 08 / 2018$ & 87.18 & 28.06 & 59.12 \\
\hline 29 & $29 / 08 / 2018$ & 86.23 & 28.05 & 58.18 \\
\hline 30 & $30 / 08 / 2018$ & 87.4 & 28.02 & 59.38 \\
\hline & Total & $\mathbf{2 5 9 5 . 9 9}$ & $\mathbf{8 1 3 . 9 4}$ & $\mathbf{1 7 8 2 . 0 5}$ \\
\hline & Average & 86.533 & $\mathbf{2 7 . 1 3}$ & 59.40 \\
\hline
\end{tabular}

connected across it, during off-peak hours D-STATCOM can charge the capacitor or energy storage bank by taking active power from the system. The active and reactive power equations are as follows:

$$
P=\frac{V E}{X} \sin \alpha
$$

Where $P$ is the active power and $\alpha$ is the angle between voltage and current of D-STATCOM.

$$
Q=\frac{V^{2}}{X}-\frac{V E}{X} \cos \alpha
$$

As per the data accumulated from the SLDC Aizawl, Mizoram the total peak load demand of Mizoram is 86.525 MW/day or $2595.77 \mathrm{MW} /$ month during August 


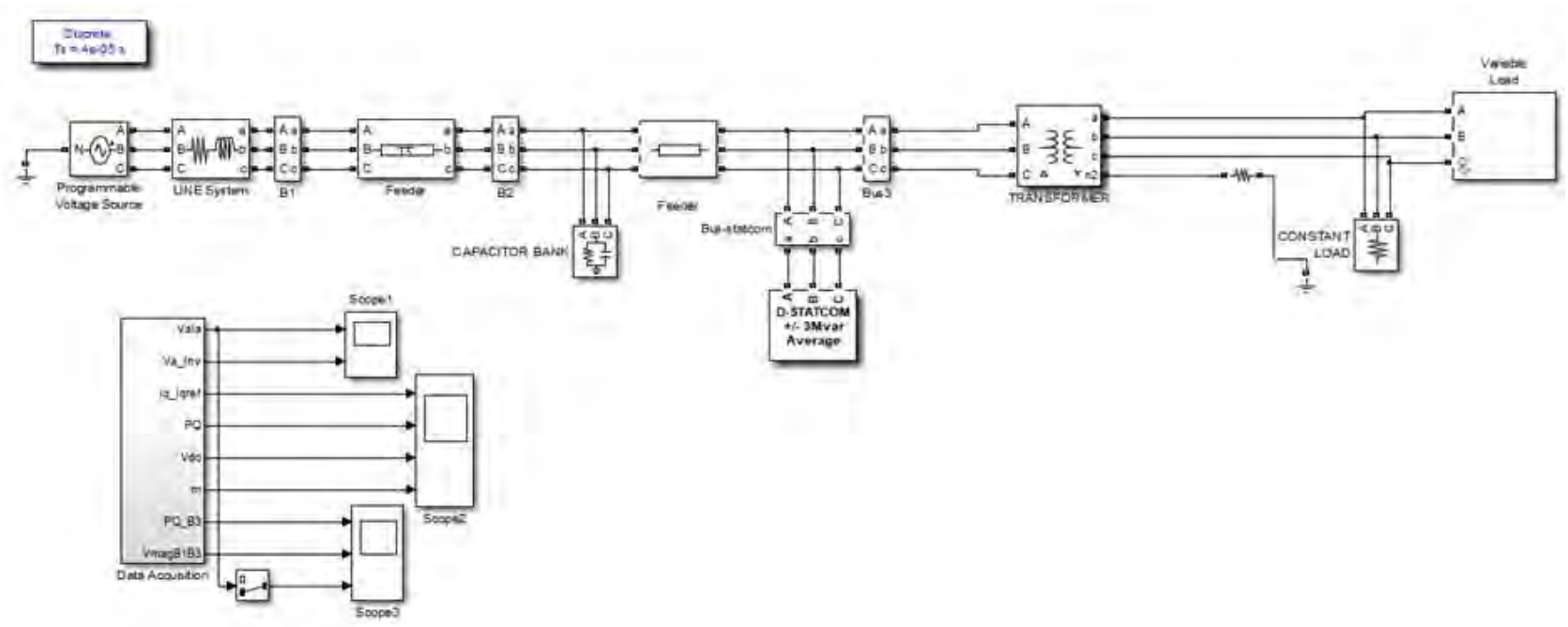

Figure 2: MATLAB simulation model of D-STATCOM in consideration with distribution scenario in Mizoram.

2018 out of which approximately $30-35 \%$ of demand is supplied by local generation and the rest is satisfied by the power grid. Around $65-70 \%$ demand of Mizoram is fulfilled by the power grid through Zuangtui sub-station, and then it is provided to various distribution substations across Mizoram. As per the data collected, the general power factor of Mizoram is 0.9 (lagging) and the highest loading recorded was $83 \%$ in Durtlang area during January 2018. The average loading across various distribution transformers in Mizoram is around $77-80 \%$. The voltage level reaching at consumer end directly depends on grid voltage and there is very few power conditioning equipment installed in the existing system which results in frequent power cuts during high load (load > $80 \%$ ) and voltage imbalances.

\section{Some statistics about Mizoram power scenario}

- Power factor in Mizoram is 0.9 (lag.) as per the standards set by Joint Electricity Regulatory Commission (JERC) for the states of Mizoram and Manipur.

- Highest loading observed was eighty-three percent $(83 \%)$ of peak load in some areas.

- Voltage variation limit is $33 \pm 9 \%$ in $\mathrm{KV}$ rating as JERC standards.

- General power frequency in Mizoram varies between 49.72 to $50.15 \mathrm{~Hz}$.

\section{RESULTS}

The phase A voltage and current waveforms of DSTATCOM along with the inverter output voltage are depicted in Figure 2. The simulation starts at time $t=0$ and it takes 0.1 to 0.2 seconds to get stable, at $\mathrm{t}=0.5 \mathrm{sec}$. and $t=0.7 \mathrm{sec}$. we varied the supply voltage by $\pm 10 \%$ and the results are shown in Figure 2. It clearly states that during steady-state operation the current of D-STATCOM is zero and at the time of instability we can see that STACOM is supplying current to maintain the voltage at the desired level and inverter output responds according to D-STATCOM to make the system stable.

In Figure 3 we can notice that lq and Iqref are varying according to the need to stabilize the voltage profile. As we can see the real power is almost constant but slight variations are happening in accordance with the $\mathrm{Vdc}$ in the next graph. As per the discussion in Fig. 2 we can clearly see that the reactive power is varying accordingly. In the last graph, we can see that the modulation index is varying from 0.7 to 0.5 for compensation and the modulation index goes up to 0.2 for compensation.

From the Figure 4 the last curve is the compensation current of the D-STATCOM which is verified above in Figure 2 . The second curve shows the voltage fluctuations across the distribution line which has been stabilized by D-STATCOM and finally active and reactive power reaching at bus (B3) for consumers is quality power without any disturbances as verified by the first curve.

\section{DISCUSSION}

It is very clear from the above-stated facts that the voltage fluctuation sat the consumer end is mitigated to a significant extent with the application of D-STATCOM in existing distribution system which will enhance the power quality and satisfy the consumers to great extent by increasing the life expectancy of their electrical and electronic equipment. D-STATCOM is a fascinating technology to be used in the distribution network of Mizoram as it provides control of reactive power compensation which in turn provide compensation for voltage flicker. 


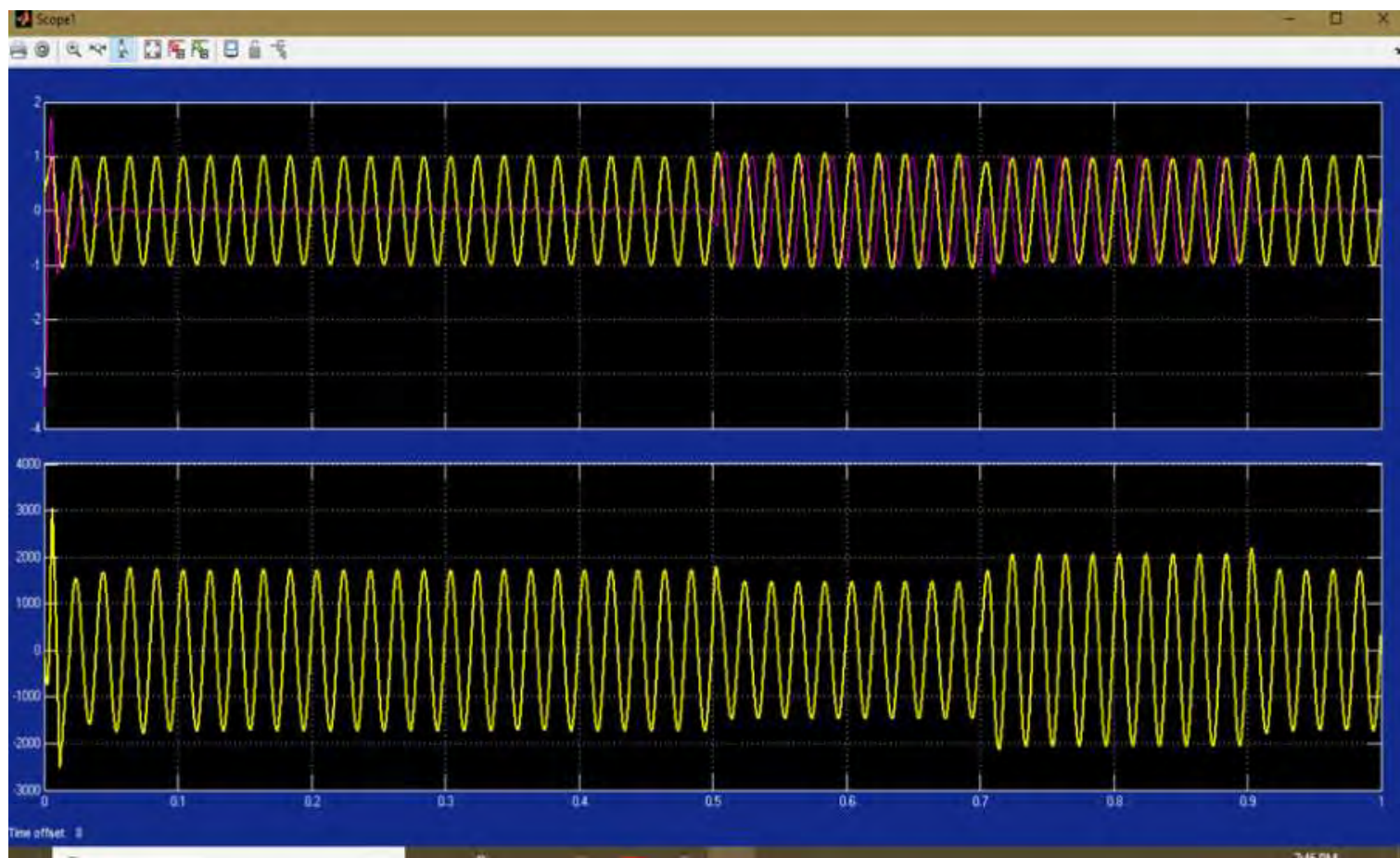

Figure 2: Output of scope 1.

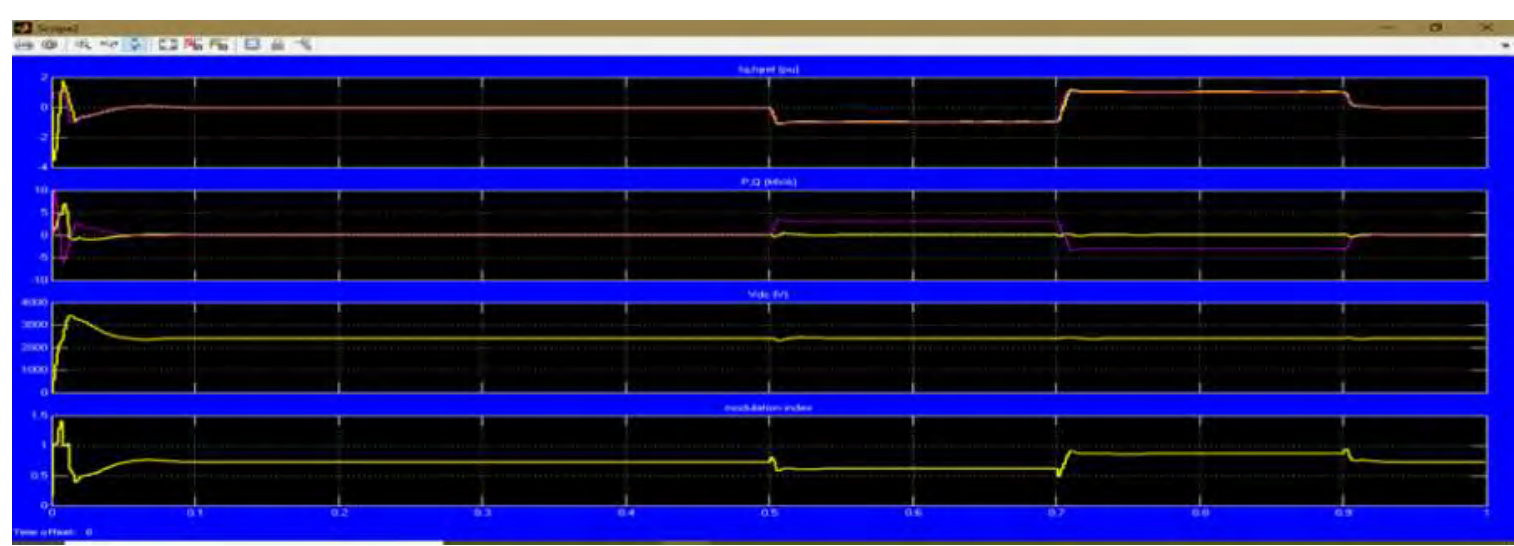

Figure 3: Output of scope 2.

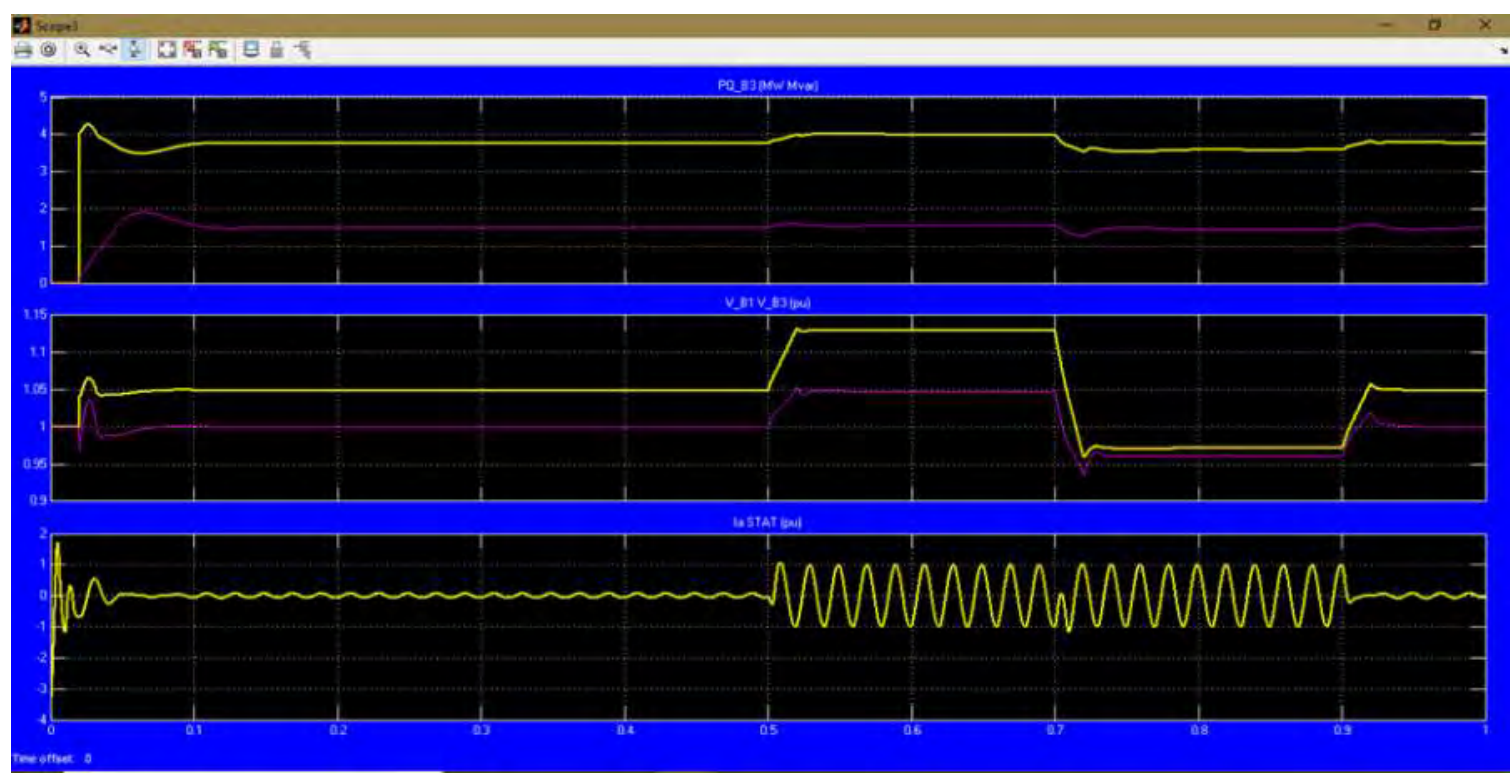

Figure 4: Output of scope 3. 


\section{ACKNOWLEDGEMENT}

The authors would like to express their gratitude to National Institute of Technology, Mizoram and Prof. Saibal Chatterjee Department of EEE NIT Mizoram for his support. We would also like to express our gratitude towards the officers and staff of SLDC, Aizawl and Zuangtui sub-station for their kind support.

\section{REFERENCES}

Census (2011). Office of the Registrar General and Census Commissioner, India (2011 Indian census).

Hingorani, N. G., Gyugyi, L. (2001). Understanding FACTS: Concepts and technology of flexible AC transmission systems. Delhi: IEEE Press.

Indian Electrical Equipment Industry Mission Plan 2012 2022 (Ministry of Heavy Industries and Public Enterprises)

Lee, T., Hu, S., Chan, Y. (2010). Design of D-STATCOM for voltage regulation in Microgrids. 2010 IEEE Energy Conversion Congress and Exposition. doi:10.1109/ ecce.2010.5618339

Lee, T., Hu, S., Chan, Y. (2013). D-STATCOM With Positive -Sequence Admittance and Negative-Sequence Conductance to Mitigate Voltage Fluctuations in HighLevel Penetration of Distributed-Generation Systems. IEEE Transactions on Industrial Electronics, 60(4), 1417-1428.
NEDP. New Economic Growth Policy (Comprehensive Growth Strategy For Mizoram).

Reed, G., Greaf, J., Matsumoto, T., Yonehata, Y., Takeda, M., Aritsuka, T Nebecker, C. (n.d.) . Application of a 5 MVA, $4.16 \mathrm{kV}$ D-STATCOM system for voltage flicker compensation at Seattle Iron and Metals. 2000 Power Engineering Society Summer Meeting (Cat. No.00CH37134). doi:10.1109/pess.2000.868768

Saravanan, S., Kannan, S., Amosedinakaran, S., Thangaraj, C. (2014). Indias electricity demand estimation using Genetic Algorithm. 2014 International Conference on Circuits, Power and Computing Technologies [ICCPCT-2014]. doi:10.1109/iccpct.2014.7054814

Sensarma, P., Padiyar, K., \& Ramanarayanan, V. (2001). Analysis and performance evaluation of a distribution STATCOM for compensating voltage fluctuations. IEEE Transactions on Power Delivery, 16(2), 259-264. doi:10.1109/61.915492

Wang, Y., Tang, J., Qiu, X. (2011). Analysis and control of D-STATCOM under unbalanced voltage condition. 2011 International Conference on Mechatronic Science, Electric Engineering and Computer (MEC). doi:10.1109/mec.2011.6025788 